\title{
Application of Selenium Nanoparticles on Sperm Quantity Indicators in Wistar Rat
}

\author{
Ebrahim Talebi (iD ${ }^{1,}$, , Habibeh Ghazanfarpour (iD) ${ }^{2}$, Reyhane Ghazanfarpoor (iD) ${ }^{2}$, Salim Bouchentouf \\ (iD) ${ }^{3,4}$ and Maryam Khosravinezhad (iD ${ }^{5}$ \\ ${ }^{1}$ Department of Animal Sciences, Darab Branch, Islamic Azad University, Darab, Fars, Iran \\ ${ }^{2}$ Department of Biology, Jahrom Branch, Islamic Azad University, Jahrom, Fars, Iran \\ ${ }^{3}$ Faculty of Technology, Doctor Tahar Moulay University of Saida, Algeria, North Africa \\ ${ }^{4}$ Laboratory of Natural Products and Bioactives, University of Tlemcen, Algeria, North Africa \\ ${ }^{5}$ Department of Polymer Science, Shiraz Branch, Islamic Azad University, Shiraz, Fars, Iran \\ "Corresponding author: Department of Animal Sciences, Darab Branch, Islamic Azad University, Darab, Fars, Iran. Email: talebi226@yahoo.com
}

Received 2021 February 01; Revised 2021 March 10; Accepted 2021 March 18.

\begin{abstract}
Background: Antioxidant enzymes and selenium in semen plasma have vital effects on reducing lipid peroxidation of spermatozoid membrane in elderly organisms by preventing the destructive effects of reactive oxygen species. Therefore, the use of antioxidants and selenium is essential for normal testicular function and spermatogenesis.

Methods: In this experimental study, 44 male Wistar rats aged 2.5 months (young) and 44 male Winstar rats aged 11 months (old) were separated into 4 groups of control, placebo, experimental $1(0.2 \mathrm{mg} / \mathrm{kg} \mathrm{BW})$, and experimental 2 ( $0.4 \mathrm{mg} / \mathrm{kg} \mathrm{BW})$. Rats encountered weekly surgery after a week of receiving different treatments. Resection of their testes was used for histological studies.

Results: The number of spermatocytes, spermatid, and spermatozoa in young and old rats increased during the study period. In young rats, the highest number of these cells remarked in the third and fourth weeks of the experiment using selenium nanoparticles (ranged from 165.3 to $285.3 \times 10^{6}$ ). For old rates, the highest number of the abovementioned cells observed in the second week of the experiment (ranged from 143.3 to $146.7 \times 10^{6}$ ). Variables of treatment, week, and age presented significant effects on the number of testicular germ cells. Also, applied treatments had no significant effect on the sperm quality characteristics of rats. The number of Sertoli and Leydig cells did not show a significant difference compared to the control group. The results showed a positive and highly significant correlation between spermatozoid, spermatocytes, and spermatocytes. The findings also indicated the same genetic and environmental effects on the traits. Therefore, any spermatocyte shift will have a direct influence on the spermatozoid. Conclusions: This study demonstrated that using selenium nanoparticles in young and old age groups in rats could improve testicular germ cells, especially in the old group. Therefore, with growing age and decreasing sperm quality, selenium nanoparticles can be used due to their positive effect on sperm parameters and their low health risk.
\end{abstract}

Keywords: Spermatogenesis, Reactive Oxygen Species, Selenium, Nanoparticles

\section{Background}

Selenium is an essential trace substance involved in a range of biochemical and physiological processes, so that its deficiency may cause several problems. The selenium supplements are necessary for improving the reproductive function of many species (1-5). In addition, they have a vital role in human and animal bodies to make selenoproteins as enzymatic compounds (6). Selenium also contributes to selenoproteins production, which makes up the bulk of the mitochondrial capsule in the middle region of the sperm. Selenium deficiency in rats leads to abnormal deformity of sperm (shape and immobile tails) with increased fragility of the spermatozoon capsule (7). There- fore, in addition to the role of this element in energy production, sperm motility, and spermatogenesis, it can affect testicular tissue, which depends on its optimal level. This element is part of enzymes such as GPx1, GPx3, mGPx4, cGPx4, and GPx5, which protect sperm from oxidative damage throughout puberty (8).

Recently, CatSpers 1- 4 have been classified as a family of sperm-specific cation channels. These proteins are voltagedependent ion channels that regulate sperm motility. Ren et al. (9) identified gene 1 , which not only plays a function in controlling sperm motility, but also encodes a calcium channel in the sperm tail by regulating the calcium flow into the sperm. The calcium ions control spermatozoid 
motility by affecting the spermatozoid tail. It worth noting that this channel is expressed exclusively in the testis tissue.

The reactive oxygen species (ROS) can have beneficial and detrimental effects on sperm function, which vary according to the type and concentration of ROS and exposure duration. Sperms produce a small quantity of ROS under physiological conditions, which is essential for sperm capacity and acrosomal reaction. On the other hand, sperm and white blood cells can produce ROS, which in turn cause damages to sperm cells by reacting with cellular macromolecules (10).

Susceptibility to oxidative stress varies depending on the sperm maturation stage. In the first stage of differentiation, in which cell divisions are actively occurring, DNA is the target of ROS for mutation. Cytoplasm plays an active protective role, and there are various checkpoints for repairing possible defects. During puberty, the cytoplasm shrinks, and the cells have less protection against ROS. Finally, in the dense phase of sperm DNA, the plasma membrane is enriched by phospholipids with the highest amount of saturated fatty acids, which causes sperm sensitization to oxidative damage $(11,12)$. Selenium catalyzes the breakdown of lipid peroxides and hydrogen peroxide (13). Research has shown that selenium supplementation could improve reproductive function and reported its necessity for normal testicular development and spermatogenesis in rats, mice, and pigs $(14,15)$. Most antioxidants change throughout the life of organisms, and glutathione peroxidase activity decreases with age (16).

This experiment was performed on rats because animal models are appropriate for investigating the condition of the reproductive glands in the spermatogenesis of humans and rodents (17). As rats grow throughout their life, degenerative changes in testicular tissue cause decreased quality of sperm (17-22). One of the factors that have a toxic effect on sperm quality is increased oxygenfree radicals. However, small amounts of these radicals are necessary for sperms to achieve fertility. In contrast, in large amounts, it must be constantly inactivated to obtain normal cell function (22). An animal study reported that aged pigs had decreased antioxidant enzyme activity (23). In farm animals, it is vital to use adequate selenium amount, mainly as a dietary supplement, to maintain health and beneficial reproduction (24).

\section{Objectives}

The effects of nanoparticles on the cellular and tissue surface have not been fully understood. However, it seems that this technology can be a useful step in preventing infertility in males (25). The present study aimed to investi- gate the changes in sperm cell count after using 0.2 and 0.4 $\mathrm{mg} / \mathrm{kg}$ of selenium nanoparticles.

\section{Methods}

\subsection{Laboratory Animals and Rearing House}

In this experimental study, 44 male Wistar rats aged 2.5 months $(200 \pm 10 \mathrm{~g})$ and 44 male Winstar aged 11 months were obtained from the Laboratory Animal Breeding Center of the Faculty of Veterinary Medicine, Shiraz University (Iran). During the adaptation period, animals were kept in the animal house of Islamic Azad University, Darab Branch, for two weeks before the experiment and pelleted feed was used. Ambient temperature and the humidity were $22{ }^{\circ} \mathrm{C}$ and 50 - 55\%, respectively. A 12/12 dark/light cycle was applied for all animals. The air in the room was ventilated by two ventilators embedded on either side of the room, and the floor of the equipment was disinfected. Water and feed were available to the animals without any restrictions (ad libitum). The animal cages were made of transparent Macrolon with dimensions of $55 \times 30 \times 20 \mathrm{~cm}$ with a mesh roof. The floors of the cages were covered with sawdust and wood chips, and the cages were cleaned and disinfected once every two days. Before beginning and during the experimental period, all rats were weighted twice a week. Before weighting each rat, the digital scale was calibrated.

\subsection{Animal Grouping}

In the present study, 88 Wistar male rats were randomly divided into 4 groups, with 11 rats in each group. The experimental diets was applied for 42 days. To determine the dose of the extract, the LD50 method was used. The experimental treatments were given to rats by nasogastric tube or NG tube (gavage). The treatment groups were included: (1) control group (received only pelleted feed and water daily); (2) placebo group [received only solvent (distilled water) daily]; (3) experimental group 1 (0.2 mg/kg body weight per day of selenium nanoparticles); and (4) experimental group $2(0.4 \mathrm{mg} / \mathrm{kg}$ body weight per day of selenium nanoparticles).

\subsection{Production Method of Nano-selenium}

To prepare selenium nanoparticles, the method of reducing selenium oxide was applied using ascorbic acid according to Zhang et al.'s method (26). At first, ascorbic acid solutions were prepared with a molecular weight of 176.12, Sigma Company with catalog number 1043003 and selenium dioxide with a molecular weight of 110.96 , Sigma Company with catalog number 200107. To prepare $3 \mathrm{~g}$ of selenium nanoparticles, $4.261 \mathrm{~g}$ of selenium dioxide was added in $1900 \mathrm{~mL}$ of distilled water. Afterward, the 
ascorbic acid solution was added to the selenium dioxide solution. The final concentration of selenium dioxide in $2000 \mathrm{~mL}$ of the volume was $0.0135 \mathrm{~mol}$ and reached 0.054 mol. The red nano-selenium particles begun to form after adding ascorbic acid, which changed the color of the solution from a colorless to a red state, indicated the solution containing selenium dioxide in monoclinic and amorphous forms (26). The prepared solution was placed in a quiet place to make nanoparticles for 12 - 44 hours. The obtained selenium nanoparticles were approved by electron microscopy (SEM) in a size of $100 \mathrm{~nm}$.

\subsection{Method of Preparing and Studying Slides of TesticularTissue}

The samples were collected on day 42 (27) for histological studies. The testes were withdrawn from the rats and placed in a container containing $10 \%$ formalin. After tissue passage, paraffin blocks and tissue sections, with a thickness of 5 microns, were developed by a microtome device. The tissue samples were analyzed under a light microscope using hematoxylin-eosin staining. Slides fixed from the cross-sections of the left and right testes of rats were studied separately by light microscopy at 40X magnification. In each slide, the number of spermatogonia, spermatocytes, spermatids, spermatozoa, Sertoli, and Leydig cells was counted with a magnification of $40 \times$. A graticule lens and a Nikon camera microscope were operated to prepare the photomicrograph (Figures 1 - 4).

\subsection{Ethical Consideration}

In all stages of the experiment, the principles of working with laboratory animals in accordance with the law on care and working with laboratory animals were observed. Besides, the principles of the Research Ethics Committee of the Islamic Azad University (IAU) were followed.

\subsection{Statistical Analysis Method}

This study was performed as a $2 \times 4$ factorial experiment following a completely randomized design (CRD). The results concerning the mean number of spermatogonia, spermatocyte, spermatid, spermatozoid, Leydig, and Sertoli in different groups were statistically analyzed. Data related to cell counts were analyzed separately by SAS and compared through Duncan test.

\section{Results}

\subsection{Number of Spermatogonia and Spermatocyte}

For both young and old rats, the number of spermatocytes, spermatids, and spermatozoids increased during the study period. The highest number of the abovementioned cells remarked in young rats in the third and fourth weeks of the experiment using selenium nanoparticles (ranged from 165.3 to $285.3 \times 10^{6}$ ). But in old rates, the highest number of mentioned cells was observed in the second week of the experiment (ranged from 143.3 to $146.7 \times 10^{6}$ ). The effects of treatment, week, and age of rats on the number of testicular germ cells were statistically significant(Table 1 and Figure 5).

According to the findings, the number of spermatogonia and spermatocyte was not significantly different between the experimental and control groups, based on the age group $(\mathrm{P}>0.05)$ (Table 2$)$. The age difference reduced the number of sex cells, but in old rats, the average number of spermatid and spermatozoid was increased with the consumption of selenium nanoparticles. Thus, the number of spermatids rose from 34.17 to $113.30 \times 10^{6}$, and the spermatozoid recorded the range of 43.75 to $125.00 \times 10^{6}$. The ratio of changes in spermatogonia and spermatocyte between the two age groups, using different treatments, ranged from 68.61 to 89.73 (with a difference of 21.12) and 60.74 to 86.61 (with a difference of 25.87), respectively.

\subsection{Number of Spermatid}

Different treatments did not have a significant effect on the mean spermatid in the young rats $(\mathrm{P}>0.05)$. But numerically, the lowest spermatid was recorded in the control group $\left(133.33 \times 10^{6}\right)$, but $0.4 \mathrm{mg} / \mathrm{kg}$ of selenium nanoparticles was observed as the highest value $\left(169.90 \times 10^{6}\right)$. The number of spermatid in old rats ranged from 34.17 to 113.30. Selenium nanoparticles exhibited a highly significant difference in spermatid $(\mathrm{P}<0.01)$. The spermatid ratio showed a range of variation from 21.68 to 66.69 in young and old rats (with a difference of 45.01). The 45.01 difference between the lowest and highest recorded ratios indicated the effectiveness of selenium nanoparticles (Table 2). With the use of nano-selenium, the number of spermatid cells in old rats showed an increasing trend (Figure 6), so that the number of these cells increased from 34.17 to $113.30(\mathrm{P}<0.05)$.

\subsection{Number of Spermatozoid}

Selenium nanoparticles had no significant effect on the mean spermatozoid in young rats compared to the control and placebo groups. Old rats showed highly significant differences in spermatozoid after receiving different treatments $(\mathrm{P}<0.0004)$. Thus, the minimum and the maximum number of these cells were 43.75 and 125.00 , respectively. Recorded ratio changes of spermatozoid ranged from 23.37 to 59.38 in young and old rats (with a difference of 36.01), respectively. There was a significant positive correlation between spermatid and spermatozoid, and changes in these two cell types were not unexpected 


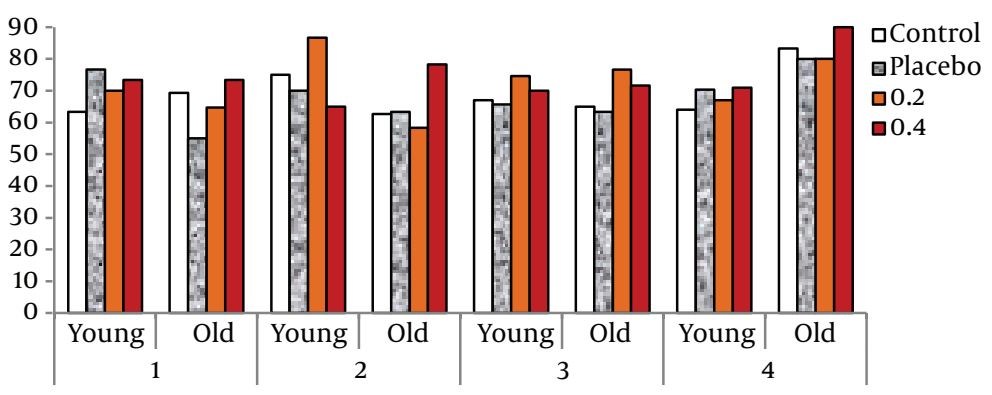

Spermatogonia
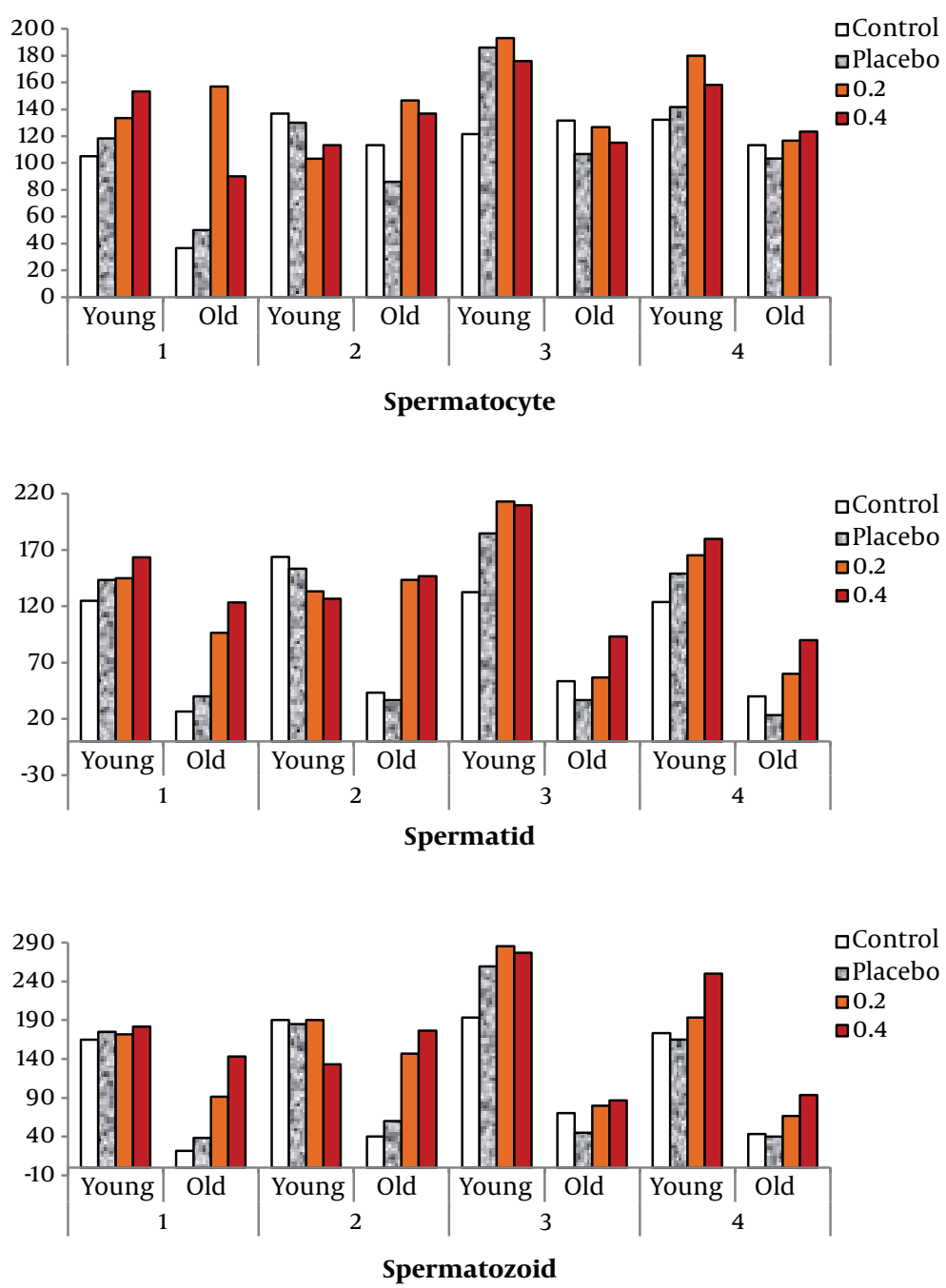

Figure 1. Photomicrograph of testicular tissue in a control group of young rat; Magnification 100X, hematoxylin-eosin staining. 


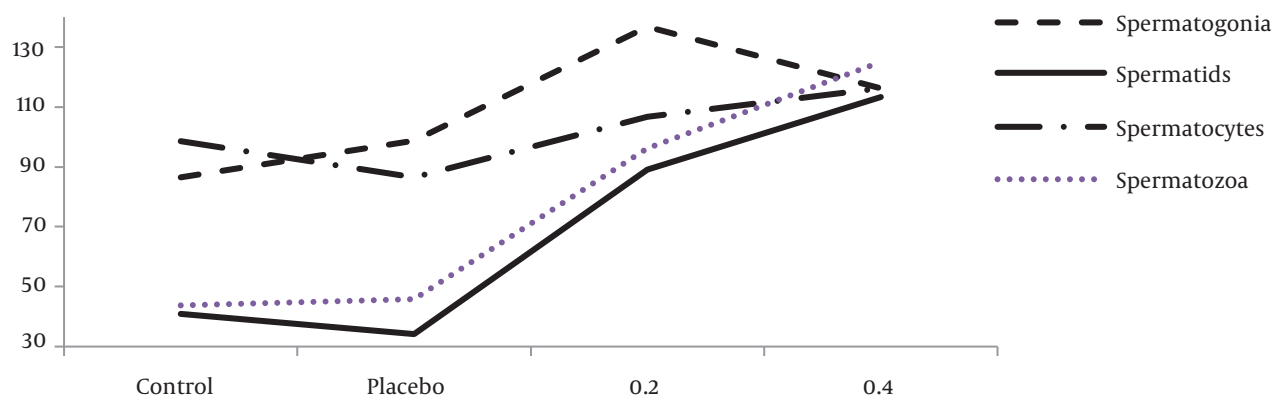

\begin{tabular}{|c|c|c|c|c|c|c|c|c|c|}
\hline \multirow{2}{*}{ Treatment } & \multicolumn{3}{|c|}{ Spermatogonia } & \multicolumn{2}{|c|}{ Spermatocyte } & \multicolumn{2}{|c|}{ Spermatid } & \multicolumn{2}{|c|}{ Spermatozoid } \\
\hline & Young & & Old & Young & Old & Young & Old & Young & Old \\
\hline \multicolumn{10}{|l|}{ Control } \\
\hline Week 1 & 63.3 & & 69.3 & 105.0 & 36.7 & 125.0 & 26.7 & 165.0 & 21.7 \\
\hline Week 2 & 75.0 & & 62.7 & 136.7 & 113.3 & 164.0 & 43.3 & 190.0 & 40.0 \\
\hline Week 3 & 67.0 & & 65.0 & 121.7 & 131.7 & 132.7 & 53.3 & 193.3 & 70.0 \\
\hline Week 4 & 64.0 & & 83.3 & 132.3 & 113.3 & 123.7 & 40.0 & 173.3 & 43.3 \\
\hline \multicolumn{10}{|l|}{ Placebo } \\
\hline Week 1 & 76.7 & & 55.0 & 118.3 & 50.0 & 143.3 & 40.0 & 175.0 & 38.3 \\
\hline Week 2 & 70.0 & & 63.3 & 130.0 & 86.0 & 153.3 & 36.7 & 185.0 & 60.0 \\
\hline Week 3 & 65.7 & & 63.3 & 186.0 & 106.7 & 184.7 & 36.7 & 259.3 & 45.0 \\
\hline Week 4 & 70.3 & & 80.0 & 141.7 & 103.3 & 149.0 & 23.3 & 165.0 & 40.0 \\
\hline \multicolumn{10}{|l|}{0.2} \\
\hline Week 1 & 70.0 & & 64.7 & 133.3 & 157.0 & 145.0 & 96.3 & 171.7 & 91.3 \\
\hline Week 2 & 86.7 & & 58.3 & 103.3 & 146.7 & 133.3 & 143.3 & 190.0 & 146.7 \\
\hline Week 3 & 74.7 & & 76.7 & 193.0 & 126.7 & 213.0 & 56.7 & 285.3 & 80.0 \\
\hline Week 4 & 67.0 & & 80.0 & 180.0 & 116.7 & 165.3 & 60.0 & 193.3 & 66.7 \\
\hline \multicolumn{10}{|l|}{0.4} \\
\hline Week 1 & 73.3 & & 73.3 & 153.3 & 90.0 & 163.3 & 123.3 & 181.7 & 143.3 \\
\hline Week 2 & 65.0 & & 78.3 & 113.3 & 136.7 & 126.7 & 146.7 & 133.3 & 176.7 \\
\hline Week 3 & 70.0 & & 71.7 & 176.0 & 115.0 & 209.7 & 93.3 & 277.0 & 86.7 \\
\hline Week 4 & 71.0 & & 90.0 & 158.3 & 123.3 & 180.0 & 90.0 & 250.0 & 93.3 \\
\hline \multicolumn{10}{|l|}{ P-value } \\
\hline Treatment & & 0.90 & & & & & & & \\
\hline Age & & 0.36 & & & & & & & \\
\hline Week & & 0.23 & & & & & & & \\
\hline Treatment $\times$ age & & 0.26 & & & & & & & \\
\hline
\end{tabular}

(Tables 2, 3, and 4). Photomicrographs scanned from testicular sections in different groups showed an increase in the number of spermatozoids in the experimental groups of older rats (Figures 1-4).

\subsection{Number of Sertoli and Leydig}

The treatments had no significant effect on the Sertoli and Leydig in experimental rats in both age groups (Table 5). The number of Sertoli in young rats ranged from 19 to 20 , which differed from older rats (13 - 14). The consumption of selenium nanoparticles did not have a significant effect on Leydig cells, and Leydig cells did not affect by age $(\mathrm{P}>0.05)$.

\subsection{Correlation and Regression Equations}

There was no linear relationship between spermatogonia and spermatocyte. The points on the coordinate axis were scattered, with no particular pattern. There was no significant correlation between spermatogonia with other mentioned cells (spermatocyte $\mathrm{P}=0.418$; spermatid $\mathrm{P}=$ 0.713 ; spermatozoid $\mathrm{P}=0.783$ ). The spermatocyte with spermatid and spermatozoid showed a positive and significant 


\begin{tabular}{|c|c|c|c|c|c|}
\hline \multirow[t]{2}{*}{ Number/Groups } & \multirow[t]{2}{*}{ Young } & \multirow[t]{2}{*}{ Old } & \multirow[t]{2}{*}{ RCTA } & \multicolumn{2}{|c|}{ Probability Level } \\
\hline & & & & Young & Old \\
\hline Spermatogonia & & & & 0.437 & 0.410 \\
\hline Control & 123.92 & 86.50 & 69.8 & & \\
\hline Placebo & 144.00 & 98.80 & 68.61 & & \\
\hline 0.2 & 152.40 & 136.75 & 89.73 & & \\
\hline 0.4 & 150.30 & 116.25 & 77.35 & & \\
\hline Spermatocytes & & & & 0.313 & 0.090 \\
\hline Control & 113.90 & 98.65 & 86.61 & & \\
\hline Placebo & 142.40 & 86.50 & 60.74 & & \\
\hline 0.2 & 144.00 & 106.75 & 74.13 & & \\
\hline 0.4 & 150.30 & 116.25 & 77.35 & & \\
\hline Spermatids & & & & 0.263 & 0.001 \\
\hline Control & 136.33 & $40.83^{B}$ & 29.95 & & \\
\hline Placebo & 157.58 & $34.17^{\mathrm{B}}$ & 21.68 & & \\
\hline 0.2 & 164.20 & $89.10^{\mathrm{A}}$ & 54.26 & & \\
\hline 0.4 & 169.90 & $113.30^{\mathrm{A}}$ & 66.69 & & \\
\hline Spermatozoid & & & & 0.544 & 0.0004 \\
\hline Control & 180.42 & $43.75^{\mathrm{B}}$ & 24.25 & & \\
\hline Placebo & 196.10 & $45.83^{B}$ & 23.37 & & \\
\hline 0.2 & 210.10 & $96.20^{A}$ & 45.79 & & \\
\hline 0.4 & 210.50 & $125.00^{\mathrm{A}}$ & 59.38 & & \\
\hline
\end{tabular}

Abbreviation: RCTA, the ratio of changes between the two ages.

${ }^{a}$ Columns with at least one common capital letter (A and B) in superscript do not differ significantly.

\begin{tabular}{|c|c|c|c|c|c|c|c|c|c|c|}
\hline \multirow[t]{2}{*}{ Treatment } & \multicolumn{2}{|c|}{$\mathrm{S}\left(\times 10^{6}\right) / \mathrm{mL}$} & \multicolumn{2}{|c|}{ LS (\%) } & \multicolumn{2}{|c|}{ DS (\%) } & \multicolumn{2}{|c|}{ LSD (\%) } & \multicolumn{2}{|c|}{$\operatorname{DDS}(\%)$} \\
\hline & Young & old & Young & old & Young & old & Young & old & Young & old \\
\hline Control & $180.42^{\mathrm{B}}$ & 43.75 & 81.50 & 57.00 & 10.50 & 31.00 & 6.00 & 6.50 & 2.00 & 5.50 \\
\hline Placebo & $196.10^{B}$ & 45.83 & 74.25 & 62.50 & 20.75 & 23.00 & 2.50 & 10.00 & 2.50 & 4.50 \\
\hline 0.2 & $210.10^{\mathrm{A}}$ & 107.94 & 76.00 & 82.75 & 18.00 & 14.25 & 4.00 & 2.50 & 2.00 & 0.50 \\
\hline 0.4 & $210.50^{\mathrm{A}}$ & 125.00 & 79.00 & 88.25 & 10.00 & 7.00 & 9.25 & 3.50 & 1.75 & 1.25 \\
\hline \multicolumn{11}{|c|}{$\begin{array}{l}\text { Abbreviations: } \mathrm{S} \text {, spermatozoa; } \mathrm{LS} \text {, live spermatozoa; DS, dead spermatozoa; } L S D \text {, live spermatozoa damaged; DDS, dead damaged spermatozoa. } \\
\text { a Columns with at least one common capital letter (A and B) in superscript do not differ significantly. }\end{array}$} \\
\hline \multicolumn{2}{|l|}{ Cells } & \multicolumn{3}{|c|}{ Spermatogonia } & \multicolumn{3}{|c|}{ Spermatocytes } & \multicolumn{3}{|c|}{ Spermatid } \\
\hline Spermatocytes & \multicolumn{4}{|c|}{$-0.153(0.418)$} & & & & & & \\
\hline Spermatid & \multicolumn{4}{|c|}{$-0.070(0.713)$} & \multicolumn{4}{|c|}{$0.708(0.000)$} & & \\
\hline Spermatozoid & \multicolumn{4}{|c|}{$-0.052(0.783)$} & \multicolumn{3}{|c|}{$0.685(0.000)$} & \multicolumn{3}{|c|}{$0.968(0.000)$} \\
\hline
\end{tabular}

${ }^{\text {a }}$ The numbers in parentheses indicated different statistical levels.

correlation of 0.708 and 0.685 , respectively (Table 4 ). The spermatozoid showed the highest correlation with spermatid (0.968). After determining the correlation coefficient, linear graphs and regression equations were calculated for the mentioned cells. According to $\mathrm{R}^{2}$, the determined linear relationship was valid (Figure 7).

The regression line diagram and $\mathrm{R}^{2}$ for spermatocyte and spermatid were as follow:
$Y_{1}=1.2221 X_{1}-40.935$

$\left(\mathrm{R}^{2}=0.5544 ; \mathrm{Y}_{1}=\right.$ spermatid and $\mathrm{X}_{1}=$ spermatocyte $)$

In addition, the regression line diagram and $\mathrm{R}^{2}$ for spermatid and spermatozoid were calculated as below:

$Y_{2}=1.3034 X_{2}-9.0402$

$\left(\mathrm{R}^{2}=0.9455 ; \mathrm{Y}_{2}=\right.$ spermatozoid and $\mathrm{X}_{2}=$ spermatid $)$ 


\begin{tabular}{|c|c|c|c|c|}
\hline \multirow[t]{2}{*}{ Groups } & \multirow[t]{2}{*}{ Young } & \multirow[t]{2}{*}{ Old } & \multicolumn{2}{|c|}{ Probability level } \\
\hline & & & Young & old \\
\hline Sertoli & & & 0.44 & 0.26 \\
\hline Control & 19.00 & 13.00 & & \\
\hline Placebo & 19.00 & 14.00 & & \\
\hline 0.2 & 20.00 & 14.00 & & \\
\hline 0.4 & 20.00 & 14.00 & & \\
\hline Leydig & & & 0.31 & 0.25 \\
\hline Control & 17.00 & 17.00 & & \\
\hline Placebo & 18.00 & 17.00 & & \\
\hline 0.2 & 17.00 & 18.00 & & \\
\hline 0.4 & 18.00 & 17.00 & & \\
\hline
\end{tabular}
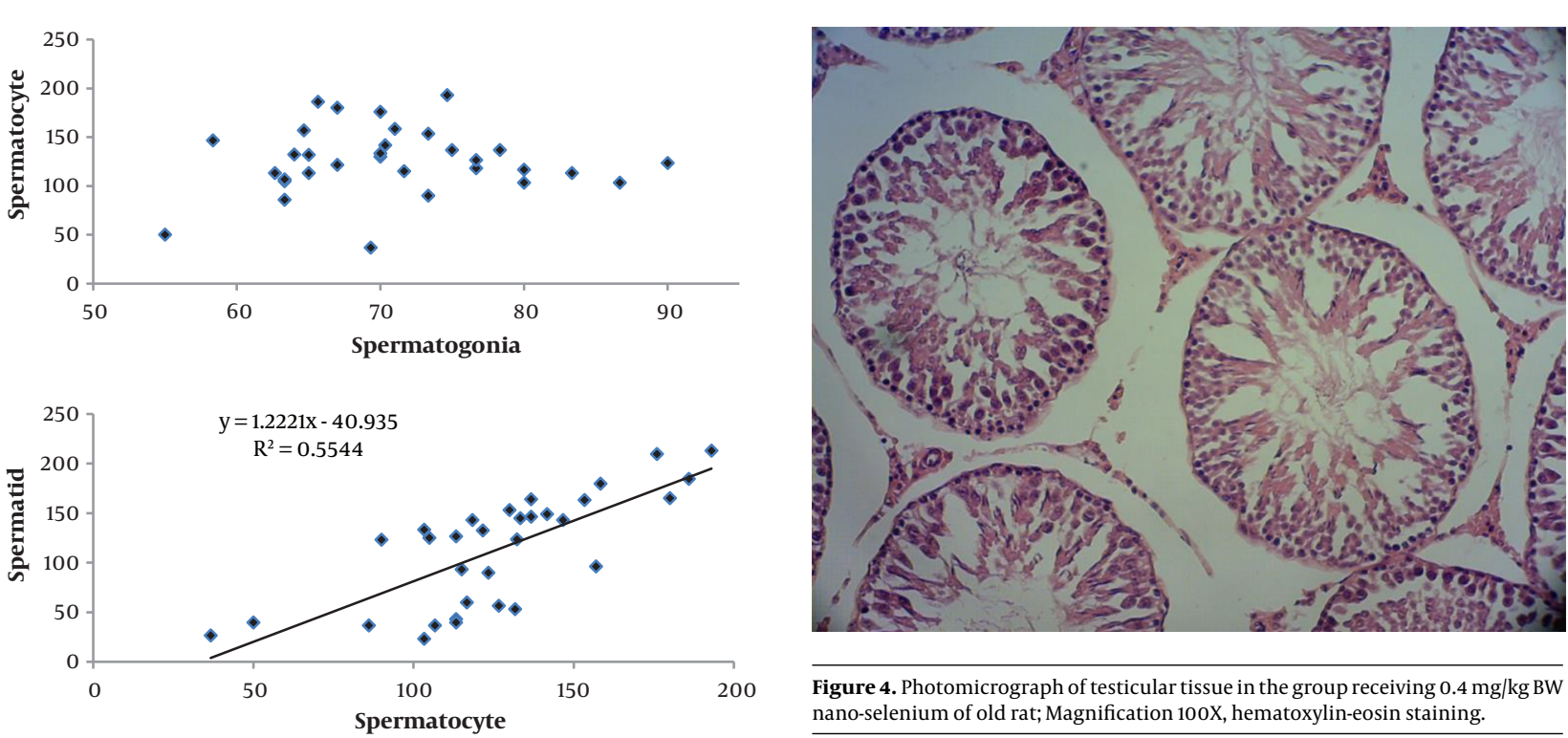

Figure 4. Photomicrograph of testicular tissue in the group receiving $0.4 \mathrm{mg} / \mathrm{kg} \mathrm{BW}$ nano-selenium of old rat; Magnification 100X, hematoxylin-eosin staining.

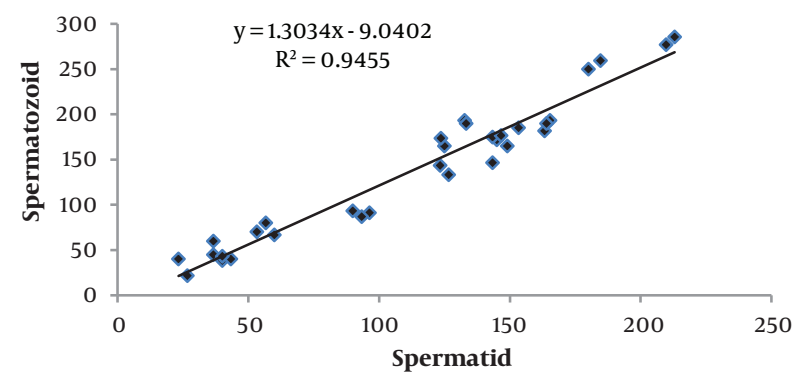

Figure 3. Photomicrograph of testicular tissue in the group receiving $0.2 \mathrm{mg} / \mathrm{kg} \mathrm{BW}$ nano-selenium of old rat; Magnification 100X, hematoxylin-eosin staining.

\section{Discussion}

As described in Tables 1 and 2, there was no difference concerning the number of spermatogonia in young rats,

which may be due to the proper functioning of the testicles of young rats and possibly the intake of sufficient amounts of antioxidants through the diet. However, in this experiment, the number of spermatogonia increased with the consumption of selenium nanoparticles. The effects of different doses of selenium on the number, motility, viability, and morphology of rat sperm have been shown and are consistent with the results of this study (28). According to the literature, the lack of selenium in the rats' diets causes damages to the seminiferous tubules, which in turn translates into reduced motility and sperm count. On the other hand, separate studies showed that high levels of selenium can harm sperm quality (7). In the present study, $0.4 \mathrm{mg} / \mathrm{kg}$ of selenium nanoparticles showed an adverse effect on rats 


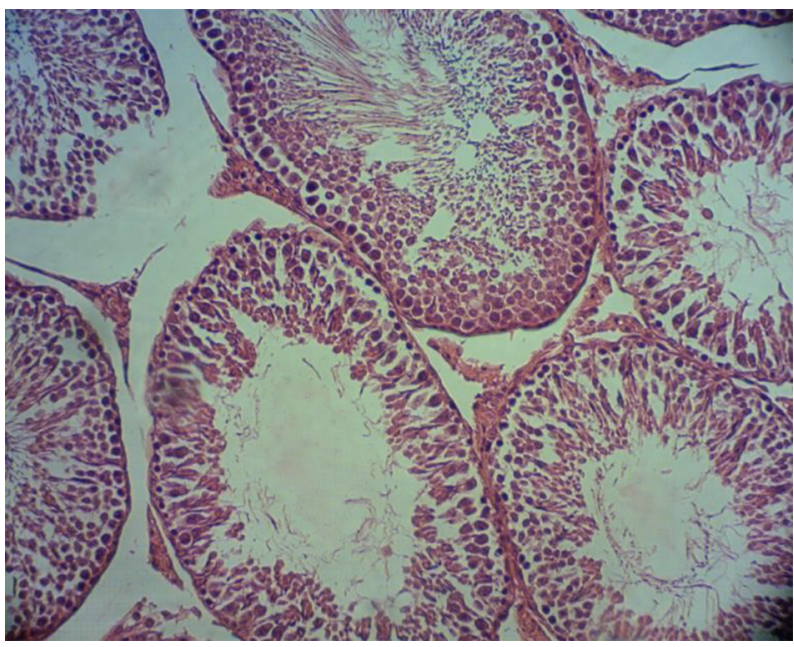

Figure 5. Comparison of the nano-selenium effect on changes in the number of spermatogonia, spermatocytes, spermatids, and spermatozoid $\left(\times 10^{6}\right)$ in different weeks

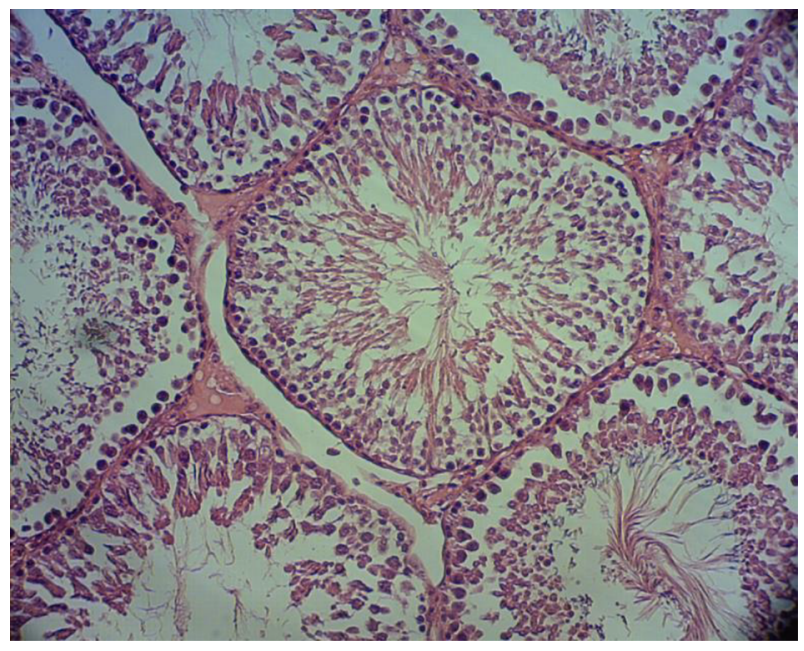

Figure 6. Changes in the use of nano-selenium on the number spermatogonia, spermatocyte, spermatid, and Spermatozoid in old rats

due to higher adsorption and much less toxicity.

For young rats, the effect of different treatments on spermatogonia and spermatocytes was not significant. Spermatocytes arise from immature spermatogonia cells. Thus, spermatocyte changes are due to spermatogonia. Primary spermatocytes perform the first stage of meiotic division and form two secondary spermatocytes. The secondary spermatocyte then transforms into two spermatid cells during the second stage of meiotic division. This stage of spermatogenesis takes place in the testes and in the transmission pathway in the epididymis (the final stage

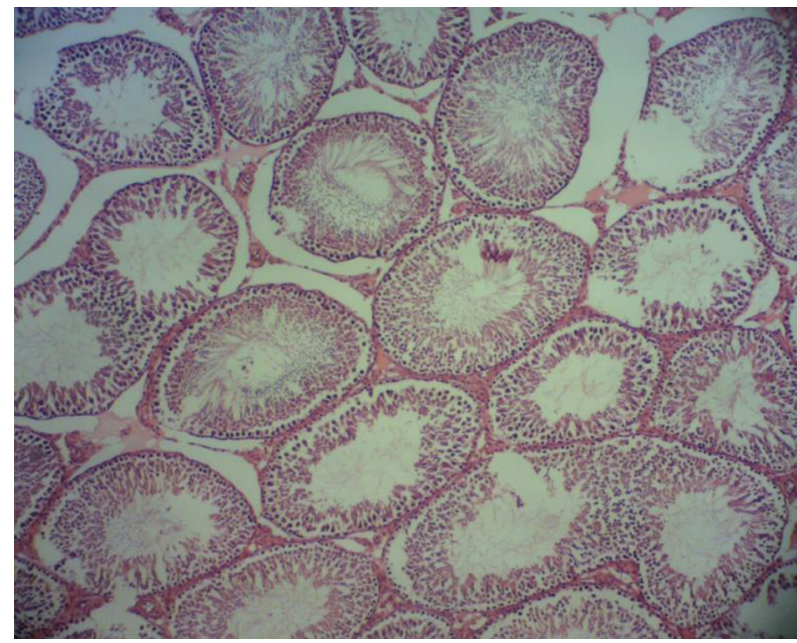

Figure 7. Graphs and regression equations between the number of spermatogonia, spermatocytes, spermatids, and spermatozoid $\left(\times 10^{6}\right)$

of sperm maturation takes place). Therefore, a high correlation between the productions of these two cells can be expected. But according to the calculated correlation, no significant relationship was observed, which indicates a greater environmental effect or measurement error at this stage. It worth noting that the complex process of spermatogenesis and the passage of germ cells to the stage of maturation of gametes depend on the protection of pathological and cytotoxic lesions, which are a threat to this phenomenon (22). Selenium concentration in testicular tissue increases during puberty and with the onset of spermatogenesis. The researcher has previously reported the supportive role of selenium and its involvement in the structure of glutathione peroxidase (15). Spermatocytes and spermatids cannot repel damage due to the specific DNA compression phase. Repair of DNA damage in these cells is less than spermatogonia, and therefore they are more exposed to oxidative stress (29). During these stages, the cytoplasm decreases, and the cells have less protection against ROS. Finally, the spermatid membrane is enriched by phospholipids with the unsaturated fatty acids in the DNA density phase (12). Selenium nanoparticles showed a positive effect on spermatozoid in old rats. This element raised the live sperm ratio and decreased the proportion of damaged and dead spermatozoid. Older rats could respond positively to selenium nanoparticles due to reduced spermatogenesis and lack of antioxidants.

The presence of antioxidants is essential for the DNA densification phase. DNA of spermatozoid is usually protected and compacted by seminal plasma antioxidants (30). During the process of spermatogenesis, the sperm 
loses a significant volume of its antioxidants along with cytoplasm, which causes their sensitivity to oxidative stress. Spermatozoid can be well protected against oxidative stress and the maturation of cytoplasmic droplets in sperm due to the immersion in seminal fluid, which contains abundant antioxidants. Therefore, consumption of natural antioxidants, such as selenium, can contribute to sperm health (10).

Due to their size, selenium nanoparticles can pass the cell membranes, which results in stimulation of the activity and expression of antioxidant enzyme genes, as well as inhibition of the process of spermatogenesis by interrupting the process of cell apoptosis. One of the selenium functions is to protect the antioxidant system and to repair the integrated spermatid structure by regulating the expression of selenoenzyme genes (24). The glutathione peroxidase enzyme is protected by the meiotic and mitotic divisions and preventing the destructive effects of DNA breakage. It also prevents damage to sperm by protecting the cell membrane and maintaining its fluidity and stability $(29,31)$. These particles not only can maintain serum testosterone levels but also minimize oxidative damage to Leydig cells by enhancing the antioxidant state. Therefore, not observing an age-related reduction in Leydig cells in old rats can be attributed to the sufficient amount of consumed selenium.

Spermatogenesis, which involves complex and precise stages of differentiation in mammals, begins at puberty and continues throughout reproductive life. The slightest disorder can cause infertility. FSH and testosterone are essential for the onset and continuation of spermatogenesis. Decreased levels of these hormones can lead to abnormal spermatogenesis. Selenium affects reproductive functions such as testosterone metabolism and is a component of sperm capsule selenoprotein. Selenium administration significantly increases sperm motility and maturity (32).

Changes in sperm-producing cells in young and old rats are shown in Figures 1 - 4. The breakdown of connective tissue in spermatogenesis tubes is obvious in Figure 2, compared to Figures 1, 3, and 4. Administration of selenium nanoparticles was associated with increased Spermatogenesis compared to the control group. These results are similar to the data presented in Tables 2 and 3. According to the findings of this study, in older rats that faced decreased antioxidant capacity in semen plasma, administration of an appropriate dose of nano-selenium improved the process of spermatogenesis and increased the number of sperm cells.

\section{Footnotes}

Authors' Contribution: All authors participated equally.
Conflict of Interests: The authors declare no conflict of interest in this study.

Ethical Approval: In all stages of the experiment, the principles of working with laboratory animals in accordance with the law on care and working with laboratory animals were observed by the Research Ethics Committee of the Islamic Azad University (IAU). Besides, the current study is approved by the Research Ethics Committee of the IAU (code: IR.PNU.REC.1398.120).

Funding/Support: This research did not receive any specific grant from funding agencies in the public, commercial, or not-for-profit sectors.

\section{References}

1. Harrison JH, Hancock DD, Conrad HR. Vitamin E and selenium for reproduction of the dairy cow. J Dairy Sci. 1984;67(1):123-32. doi: 10.3168/jds.S0022-0302(84)81275-8. [PubMed: 6707299].

2. Kohle O, Ruile S, Grätzel M. Ruthenium(II) charge-Transfer sensitizers containing 4,4'-dicarboxy-2,2'-bipyridine. Synthesis, properties, and bonding mode of coordinated thio- and selenocyanates. Inorganic Chemistry. 1996;35(16):4779-87. doi:10.1021/ic9515665.

3. Mistry HD, Broughton Pipkin F, Redman CW, Poston L. Selenium in reproductive health. Am J Obstet Gynecol. 2012;206(1):21-30. doi: 10.1016/j.ajog.2011.07.034. [PubMed: 21963101].

4. Wang Y, Yang HM, Cao W, Li YB. Effect of selenium supplementation on pigeon reproductive performance, selenium concentration and antioxidant status. Poult Sci.2017;96(9):3407-13. doi:10.3382/ps/pex121. [PubMed: 28605550].

5. Khalil-Khalili AA, Zhandi M, Zaghari M, Mehrabani-Yeganeh H, Yousefi AR, Tavakoli-Alamooti M. The effect of dietary organic selenium on reproductive performance of broiler breeder roosters under dexamethasone induced stress. Theriogenology. 2021;161:16-25. doi: 10.1016/j.theriogenology.2020.11.016. [PubMed: 33278691].

6. Sunde RA. Selenium. In: Ross AC, Caballero B, Cousins RJ, Tucker $\mathrm{KL}$, Ziegler TR, editors. Modern nutrition in health and disease. 11th ed. Philadelphia, USA: Wolters Kluwer Health/Lippincott Williams \& Wilkins; 2014. p. 225-37.

7. Olson GE, Winfrey VP, Hill KE, Burk RF. Sequential development of flagellar defects in spermatids and epididymal spermatozoa of selenium-deficient rats. Reproduction. 2004;127(3):335-42. doi: 10.1530/rep.1.00103. [PubMed: 15016953].

8. Ahsan U, Kamran Z, Raza I, Ahmad S, Babar W, Riaz MH, et al. Role of selenium in male reproduction - A review. Anim Reprod Sci. 2014;146(12):55-62. doi: 10.1016/j.anireprosci.2014.01.009. [PubMed: 24613013].

9. Ren D, Navarro B, Perez G, Jackson AC, Hsu S, Shi Q, et al. A sperm ion channel required for sperm motility and male fertility. Nature. 2001;413(6856):603-9. doi: 10.1038/35098027. [PubMed: 11595941].

10. Agarwal A, Gupta S, Sharma RK. Role of oxidative stress in female reproduction. Reprod Biol Endocrinol. 2005;3:28. doi: 10.1186/1477-7827-328. [PubMed: 16018814]. [PubMed Central: PMC1215514].

11. Sikka SC. Oxidative stress and role of antioxidants in normal and abnormal sperm function. Front Biosci. 1996;1:e78-86. doi: 10.2741/a146. [PubMed: 9159248].

12. Agarwal R, Raisuddin S, Tewari S, Goel SK, Raizada RB, Behari JR. Evaluation of comparative effect of pre- and posttreatment of selenium on mercury-induced oxidative stress, histological alterations, and metallothionein mRNA expression in rats. J Biochem Mol Toxicol. 2010;24(2):123-35. doi: 10.1002/jbt.20320. [PubMed: 20143455]. 
13. Shamberger RJ. Biological interactions of selenium with other substances. Biochemistry of selenium. University of Michigan,USA: Springer; 1983. p. 125-66.

14. Combs Jr GF, Combs SB. The role of selenium in nutrition. Cambridge, Massachusetts, United States: Academic Press; 1986

15. Behne D, Weiler H, Kyriakopoulos A. Effects of selenium deficiency on testicular morphology and function in rats. J Reprod Fertil. 1996;106(2):291-7. doi: 10.1530/jrf.0.1060291. [PubMed: 8699413].

16. Lopez-Barneo J, Pardal R, Ortega-Saenz P. Cellular mechanism of oxygen sensing. Annu Rev Physiol. 2001;63:259-87. doi: 10.1146/annurev.physiol.63.1.259. [PubMed: 11181957].

17. Kidd SA, Eskenazi B, Wyrobek AJ. Effects of male age on semen quality and fertility: a review of the literature. Fertil Steril. 2001;75(2):237-48. doi: 10.1016/s0015-0282(00)01679-4. [PubMed: 11172821].

18. Homonnai ZT, Fainman N, David MP, Paz GF. Semen quality and sex hormone pattern of 29 middle aged men. Andrologia. 1982;14(2):16470. doi: 10.1111/j.1439-0272.1982.tb03119.x. [PubMed: 6808865].

19. Dondero F, Mazzilli F, Giovenco P, Lenzi A, Cerasaro M. Fertility in elderly men. J Endocrinol Invest. 1985;8 Suppl 2:87-91. [PubMed: 4031398].

20. Haidl G, Jung A, Schill WB. Ageing and sperm function. Hum Reprod. 1996;11(3):558-60. doi: 10.1093/humrep/11.3.558. [PubMed: 8671265].

21. Centola GM, Eberly S. Seasonal variations and age-related changes in human sperm count, motility, motion parameters, morphology, and white blood cell concentration. Fertil Steril.1999;72(5):803-8. doi: 10.1016/s0015-0282(99)00395-7. [PubMed: 10560981].

22. Agarwal A, Nallella KP, Allamaneni SS, Said TM. Role of antioxidants in treatment of male infertility: An overview of the literature. Reprod Biomed Online. 2004;8(6):616-27. doi:10.1016/s1472-6483(10)616410. [PubMed: 15169573].

23. Vohra BP, Sharma SP, Kansal VK. Age-dependent variations in mitochondrial and cytosolic antioxidant enzymes and lipid peroxidation in different regions of central nervous system of guinea pigs. Indian J Biochem Biophys. 2001;38(5):321-6. [PubMed: 11886080].

24. Surai PF. Selenium in poultry nutrition 1. Antioxidant properties, deficiency and toxicity. Worlds Poult Sci J. 2019;58(3):333-47. doi: 10.1079/wps20020026.

25. Falchi L, Khalil WA, Hassan M, Marei WFA. Perspectives of nanotechnology in male fertility and sperm function. Int $J$ Vet Sci Med. 2018;6(2):265-9. doi: 10.1016/j.ijvsm.2018.09.001. [PubMed: 30564607]. [PubMed Central: PMC6286411].

26. Zhang SY, Zhang J, Wang HY, Chen HY. Synthesis of selenium nanoparticles in the presence of polysaccharides. Mater Lett. 2004;58(21):2590-4. doi:10.1016/j.matlet.2004.03.031.

27. Anjamrooz SH, Movahedin M, Mowla SJ, Bairanvand SP. Assessment of morphological and functional changes in the mouse testis and epididymal sperms following busulfan treatment. Iran Biomed J. 2007;11(1):15-22. [PubMed: 18051700].

28. Mohammadi S, Movahedin M, Mowla SJ. He effects of selenium antioxidant activity on sperm parameters and testis structure in aging and adult male mice. J Reprod Infertil. 2008;3:230-8.

29. Peters L. The effect of conjugated linoleic acid on spermatogenesis [master's thesis]. Canada: University of Manitoba Winnipeg; 2011.

30. Aitken RJ, Krausz C. Oxidative stress, DNA damage and the Y chromosome. Reproduction. 2001;122(4):497-506. doi: 10.1530/rep.0.1220497. [PubMed: 11570956].

31. Rashad MM, Galal MK, Abou-El-Sherbini KS, El-Behairy AM, Gouda EM, Moussa SZ. Nano-sized selenium attenuates the developmental testicular toxicity induced by di-n-butyl phthalate in pre-pubertal male rats. Biomed Pharmacother. 2018;107:1754-62. doi: 10.1016/j.biopha.2018.09.006. [PubMed: 30257394].

32. Barrat CLR, Grudzinsky JG, Yovich JL. Spermatogenesis in gametes: The spermatozoon. Cambridge, USA: Cambridge University Press; 1995. p. 245-51. 